\title{
Mechanisms for the Formation of Acetylglycosides and Orthoesters from Acetylglycosyl Halides
}

\author{
By Horace S. Isbell and Harriet L. Frush
}

\begin{abstract}
To obtain information concerning the stereomeric factors that affect the course of replacement reactions, a study has been made of the replacement of the halogen of certain acetyglycosyl bromides by methanol in the presence of silver carbonate (the Koenigs-Knorr reaction). The investigation shows that the solvent and the temperature greatly influence the course of the reaction when the configuration is trans but have little influence when the configuration is cis. The experimental data support the concept that under definite stereomeric conditions a solvated orthoester intermediate takes part in the reaction at low temperatures. At higher temperatures part of the reaction appears to take place through a free orthoester ion. By selection of suitable experimental conditions, it was possible to direct the orthoester reaction in large measure to either the methyl orthoacetate or the methyl acetyglycoside with apparent retention of configuration.
\end{abstract}

\section{Introduction}

One of the most useful reactions for the synthesis of glycosidic compounds consists of the interaction of a substance containing a free hydroxyl group with an acetylglycosyl halide in the presence of silver carbonate or other substance capable of removing the halide ion. The reaction, commonly known as the Koenigs-Knorr reaction $[1],{ }^{1}$ leads to the formation of a number of products.

When the halogen and the neighboring acetyl group of the acetylglycosyl halide are trans, the reaction with methanol in the presence of silver carbonate produces an orthoacetate I and the anomeric acetylglycosides II and III. It was pointed out in previous publications from this laboratory $[2,3,4]$ that the orthoester is formed from trans acetylglycosyl halides by an intramolecular, opposite-face attack upon the glycosidic carbon by the nucleophilic oxygen of the neighbor-

${ }^{1}$ Figures in brackets indicate the literature references at the end of this paper.

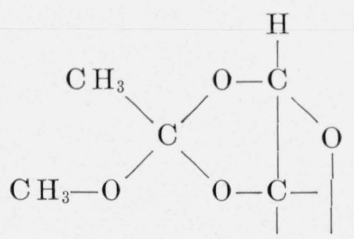

I

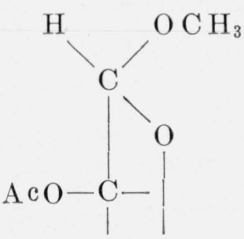

II ing acetyl group, with the addition of methanol at the carboxylate carbon and the elimination of a proton from the resultant orthoester intermediate (eq 1). The acetylglycoside of like configuration to the parent halide is formed by a secondary reaction of the orthoester intermediate with methanol at the glycosidic carbon (eq 2). The acetylglycoside of unlike configuration is formed by an intermolecular, opposite-face attack by the methanol from the environment upon the glycosidic carbon with the elimination of a proton (eq 3). The last reaction is in competition with reactions involving the orthoester intermediate.

When the halogen and the neighboring acetyl group of the acetylglycosyl halide are cis, intramolecular reaction is impossible, and no orthoester is formed. Replacement takes places by the mechanism of eq 3 , to yield the acetylglycoside of configuration opposite to that of the parent halide. 
<smiles>[R20]C(=O)OC(C)(C)OC(=O)O</smiles><smiles>[R20]C1(C)OC2CC(C)(O2)O1</smiles>

$\mathrm{RO}{ }^{!} \mathrm{H}$

$\left(\mathbf{R}=\mathrm{H}, \mathrm{CH}_{3}, \mathrm{CH}_{3} \mathrm{C}=\mathrm{O}\right.$, etc. $)$

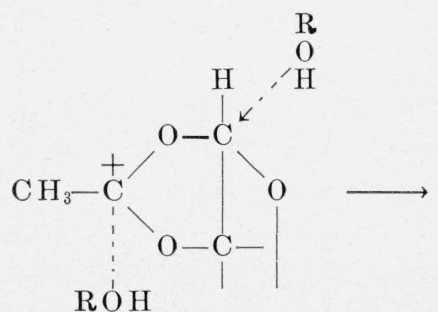<smiles>CCOC1(C)OCC(C)(OC)O1</smiles>

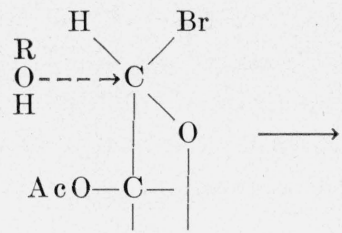<smiles>[R20]C1OCC(C)(OC)C1(C)O</smiles>

Shortly after the publication [2] presenting these mechanisms for the replacement reactions of the acetylglycosyl halides, Winstein and Buckles [5] advanced similar mechanisms to account for certain reactions outside the carbohydrate field. In reactions of the orthoester type, they emphasized the independent existence of the orthoester intermediate in the form of the ion IV. Although their mechanism does not differ markedly from that already presented, the question as to whether or not the orthoester intermediate exists in solution as a free ion or a solvated ion is of importance. In a recent publication Winstein, Hanson, and Grunwald [6] claim that results of a study of the acetolysis of trans-2-acetoxycyclohexyl- $p$-toluenesulfonate rule out the mechanism for orthoester formation symbolized by $V$, and remark that this mechanism was envisioned by one of us for orthoester formation from acetohalogen sugars. We believe that the evidence of Winstein and coworkers does not rule out the orthoester mechanism cited. In order to test the concept of a solvated orthoester intermediate, a quantitative study has been made of the KoenigsKnorr reaction, and especially of the effect of solvents and temperature upon the composition of the reaction products. The results given in this paper show that at low temperatures the reaction products vary as required by the solvated orthoester intermediate rather than by the free orthoester ion.<smiles>Cc1ccc(C)c(C)c1</smiles><smiles></smiles>

IV

\section{Role of the Solvent in the Koenigs-Knorr Reaction}

Presumably, the role of the solvent in the reactions under consideration is somewhat similar to its role in some of the more common ionization reactions. The ionization of an acid in water, for instance, involves coordination of the acidic hydrogen with water, to form an oxonium ion, accompanied by separation of the anion. Similarly, the ionization of an acetylglycosyl halide may involve coordination of the solvent at a reactive center, 
the effect of which is to facilitate release of the halogen anion.

In a trans acetylglycosyl halide, coordination of a nucleophilic solvent can occur either at the glycosidic carbon (eq 3) or at the carboxylate carbon of the neighboring acetyl group (eq 1). Presumably, coordination of the solvent with the carboxylate carbon releases electrons to the acetyl oxygen and thus increases its nucleophilic properties, and its capacity to combine with the glycosidic carbon, with release of the halogen. When the coordinating substance possesses an ionizable hydrogen, the solvated orthoester ion can yield a neutral substance by elimination of the proton. If the coordinating solvent $\mathrm{Y}$ (in place of $\mathrm{ROH}$ ) does not have an ionizable hydrogen, the orthoester intermediate cannot yield a neutral substance by elimination of a proton; hence it exists in solution until decomposed by thermal agitation or by a secondary reaction, as for instance with methanol (eq 4). The secondary reaction yields the glycoside that has the same configuration as the original acetylglycosyl halide, and the proportion of this glycoside should therefore be increased by the presence of the coordinating solvent, Y.

In a cis acetylglycosyl halide, stereomeric conditions make reaction between the glycosidic carbon and the neighboring acetyl group impossible. Hence, the mechanism of eq 4 is not applicable, and the presence of the coordinating solvent, $\mathrm{Y}$, should have no direct effect on the composition of the product.

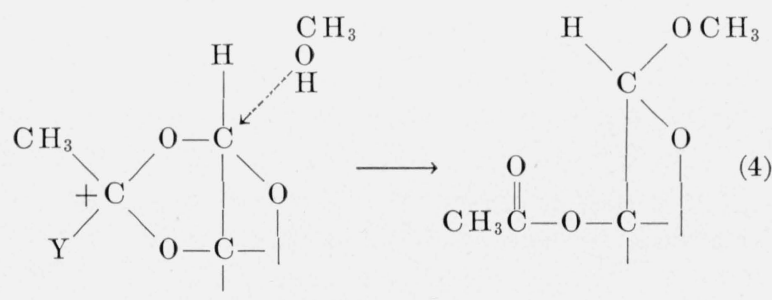

In the event that several nucleophilic substances are available for coordination with a trans acetylglycosyl halide, one can envision a competitive system in which several solvated orthoester intermediates are present. For instance, in a mixture of ether, methanol, and water, solvated orthoester intermediates can be formed from each constituent. The orthoester intermediates derived from methanol and water yield neutral compounds by elimination of a proton, as in eq
1. ${ }^{2}$ The ether-containing intermediate, however, unable to become stabilized by elimination of a proton, will exist in solution until decomposed by thermal agitation, or by reaction with either methanol or water at the glycosidic carbon, in the manner depicted in eq 4 . Thus the addition of the solvent $\mathrm{Y}$ should favor the formation of either the glycoside or the acetyl sugar having the same configuration as the parent acetylgylcosyl halide. On the other hand, if the reaction takes place through the free orthoester ion of Winstein and coworkers, the probability of the formation of either the orthoester or the acetylglycoside having the same configuration as the parent halide should be substantially independent of the presence of a solvent such as ether, which supposedly serves only as a diluent.

The foregoing considerations apply only to trans acetylglycosyl halides. We have already noted that if the acetylglycosyl halide has a cis configuration for the substituents of carbons 1 and 2, the orthoester mechanism is not applicable, and one would expect no appreciable effect of the solvent upon the character of the product formed.

\section{Effect of the Byproduct, Water, on the Koenigs-Knorr Reaction}

In addition to the alpha and beta acetylglycosides and the orthoester, which are formed in the Koenigs-Knorr reaction, two other products must be taken into consideration. These are the alpha and beta free acetylsugars, which are formed from water inevitably present as a byproduct. Theoretically, 1 mole of water is produced from 2 moles of methanol (eq 5), and 1 mole of water produces 2 moles of the free acetylsugar (eq 6). If all of the water were to react with the acetylglycosyl halide, the product would contain equal proportions of the free acetylsugar and the methoxy compounds. ${ }^{3}$ The extent of the water reaction depends in part on the manner in which the replacement is conducted. When the alcohol

\footnotetext{
2 Decomposition of the orthoacid formed from water would yield the free acetylsugar, $\mathrm{CH}_{2} \mathrm{OAc} . \mathrm{CH} .(\mathrm{CH} . \mathrm{OAc})_{3} . \mathrm{CH} . \mathrm{OH}$.

3 In the preparation of orthoesters, other workers have found it advantageous to conduct the reaction in the presence of a drying agent, ordinarily Drierite [7]. In spite of the use of the drying agent, reaction with water could not be entirely eliminated in the present study.
} 
is added slowly to the acetylglycosyl halide in another solvent, considerable opportunity is provided for the byproduct, water, to enter into the reaction, because it is in competition with a relatively small quantity of methanol. For this reason, more of the free acetylsugar should be formed when a large part of the methanol is replaced by ether or benzene. The present investigation has shown that this is indeed the case.

$$
\begin{gathered}
2 \mathrm{RBr}+\mathrm{Ag}_{2} \mathrm{CO}_{3}+2 \mathrm{CH}_{3} \mathrm{OH} \rightarrow 2 \mathrm{ROCH}_{3}+2 \mathrm{AgBr}+ \\
\mathrm{H}_{2} \mathrm{O}+\mathrm{CO}_{2} .
\end{gathered}
$$

$$
2 \mathrm{RBr}+\mathrm{Ag}_{2} \mathrm{CO}_{3}+\mathrm{H}_{2} \mathrm{O} \rightarrow 2 \mathrm{ROH}+2 \mathrm{AgBr}+\mathrm{CO}_{2} \text {. }
$$

The mechanisms that have been advanced on page 162 for the reactions of methanol with cis and trans acetylglycosyl halides apply equally well to the reactions with water. An intermolecular opposite-face attack on the glycosidic carbon of either cis or trans acetylglycosyl halides yields the acetylsugar of opposite configuration to that of the parent halide, as shown in eq 3 . Thus, an alpha acetylglycosyl halide yields the beta modification of the free acetylsugar. The trans acetylglycosyl halide reacts also by the intramolecular orthoester mechanism of eq 1 , but the orthoacid is unstable and rearranges to give the free acetylsugar (eq 7). ${ }^{4}$ Therefore this mechanism yields the same product as that produced by the intermolecular, opposite-face reaction, namely, the beta acetylsugar. That is, the alpha halide yields the beta acetylsugar by two mechanisms. In the presence of a solvent such as ether, which cannot release a proton, decomposition of the solvated intermediate can yield the alpha acetylsugar by the mechanism of eq 4 .
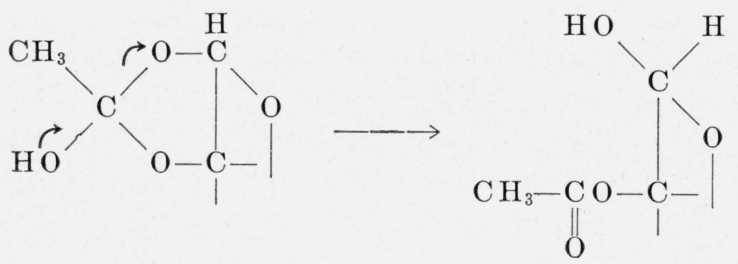

Since the free acetylsugars are interconvertible by the mutarotation reaction, the quantitative determination of the alpha and beta modifications is difficult. In this work, the sum of the two modifications has been determined by a titration method; and it has been ascertained polari-

\footnotetext{
4 The rearrangement of the orthoacid to the hydroxy compound is essentially the same as that outlined in [5].
}

metrically that the beta modification, as anticipated, predominates in the reaction product.

\section{Discussion of Experimental Results}

1. Effect of the Solvent in the Koenigs-Knorr Reaction and Evidence for a Solvated Orthoester Intermediate

The results given in table 1 show that the composition of the products from tetraacetylmannosyl bromide (a trans acetylglycosyl halide) depends on the character of the solvent and on the experimental conditions. When the solvent is methanol, the product of the intramolecular reaction at $20^{\circ} \mathrm{C}$ is largely the methyl orthoacetate; no alpha acetylglycoside is formed. The production of the orthoester without the alpha acetylglycoside shows that the orthoester intermediate decomposes only by the reaction of eq 1 , and there is no evidence for reaction at the glycosidic carbon as would be expected if the mechanism involved the free ion. The absence of a measurable quantity of the alpha acetylglycoside indicates that the orthoester intermediate loses a proton rapidly, before reaction can occur at the glycosidic carbon by eq 2 . The results also show a small amount of the beta acetylglycoside, presumably formed by the competing intermolecular reaction of eq 3 . When the methanol is largely replaced by either ether or benzene, the proportion of the orthoester decreases, and a substantial quantity of the alpha acetylglycoside appears. If the reaction took place through the free orthoester ion, one would not expect this striking change. Thus, it appears that a solvated orthoester intermediate enters into the reaction, as indicated in eq 4 . The results in table 1 show that the effect of benzene in causing formation of the alpha acetylglycoside is less than that of ether, but nevertheless considerable. The marked effect of ether upon the composition of the reaction product is in accord with its well-known tendency to coordinate. Its basic properties arise from the unshared electrons of the oxygen. Although benzene is less basic than ether, its ability to coordinate likewise accounts for the changes observed. The marked increase in the proportion of the free acetylsugar when the amount of methanol is low and the reaction is conducted in either ether or benzene shows the effect of the competition of the byproduct, water, for the reactive centers, as mentioned on page 163 . 
TABLE 1. Composition of products from reaction of acetylglycosyl bromides with methanol in the presence of silver carbonate at $20^{\circ} \mathrm{C}$

\begin{tabular}{|c|c|c|c|c|c|c|c|c|}
\hline \multirow{2}{*}{$\begin{array}{l}\text { Experi- } \\
\text { ment } \\
\text { number }\end{array}$} & \multirow[b]{2}{*}{ Solvent } & \multirow[b]{2}{*}{ Addition of methanol } & \multicolumn{4}{|c|}{ Molecular composition of product } & \multicolumn{2}{|c|}{$\begin{array}{l}\text { Optical rotation of } \\
\text { product a }\end{array}$} \\
\hline & & & $\begin{array}{l}\text { Acetyl- } \\
\text { sugar }\end{array}$ & $\begin{array}{l}\text { Acetyl- } \\
\text { orthoester }\end{array}$ & $\begin{array}{c}\text { Beta } \\
\text { acetyl- } \\
\text { glycoside }\end{array}$ & $\begin{array}{l}\text { Alpha } \\
\text { acetyl- } \\
\text { glycoside }\end{array}$ & $\begin{array}{l}{[\alpha]_{D}^{20} \text { at }} \\
60 \mathrm{~min} \\
(\mathrm{MeOH})\end{array}$ & $\begin{array}{l}{[\alpha]_{D}^{20} \text { at }} \\
\text { equilib- } \\
\text { rium } \\
\left(\mathrm{CHC} l_{3}\right)\end{array}$ \\
\hline \multicolumn{9}{|c|}{ Product from tetraacetyl- $\alpha$-D-mannosyl bromide } \\
\hline$I_{\ldots} \ldots$ & $20 \mathrm{ml}$ of methanol & Used as solvent. & $\begin{array}{l}\text { Percent } \\
\quad 6.9\end{array}$ & $\begin{array}{l}\text { Percent } \\
78.5\end{array}$ & $\begin{array}{l}\text { Precent } \\
\quad 14.6\end{array}$ & $\begin{array}{l}\text { Percent } \\
0\end{array}$ & $-32.2^{\circ}$ & $-27.7^{\circ}$ \\
\hline II ... & $20 \mathrm{ml}$ of ether $+0.5 \mathrm{ml}$ methanol. & Included in solvent. & 25.9 & 41.0 & 11.4 & 21.7 & -23.3 & -0.7 \\
\hline III $\ldots$ & $15 \mathrm{ml}$ of ether & $\begin{array}{l}0.5 \mathrm{ml} \text { of methanol in } 5 \mathrm{mi} \text { of } \\
\text { ether added dropwise over } 2 \\
\text { min. }\end{array}$ & 32.1 & 18. 5 & 18. 7 & 30.7 & -16.8 & +7.5 \\
\hline & $20 \mathrm{ml}$ of benzene $+0.5 \mathrm{ml}$ of & $\begin{array}{l}0.5 \mathrm{ml} \text { of methanol in } 5 \mathrm{ml} \text { of } \\
\text { ether added dropwise over } 18 \\
\text { min. } \\
\text { Included in solvent. }\end{array}$ & 35.4 & 7.5 & 23.1 & 34.0 & -7.3 & $\begin{array}{l}+10.6 \\
-12.3\end{array}$ \\
\hline V.... & $\begin{array}{l}20 \mathrm{ml} \text { of benzene }+0.5 \mathrm{ml} \text { of } \\
\text { methanol }\end{array}$ & Included in solvent. & 16.0 & 64.5 & 8.1 & 11.4 & -32.7 & -12.3 \\
\hline VI.- & $15 \mathrm{ml}$. of benzene & $\begin{array}{l}0.5 \mathrm{ml} \text { of methanol in } 5 \mathrm{ml} \text { of } \\
\text { benzene added dropwise over } \\
20 \mathrm{~min} .\end{array}$ & 28.7 & 36.1 & 12.9 & 22.3 & -16.0 & +0.7 \\
\hline \multicolumn{9}{|c|}{ Product from tetraacetyl- $\alpha$-D-glucosyl bromide } \\
\hline IX $\ldots$ & $20 \mathrm{ml}$ of methanol............... & Used as solvent. & 5.7 & - n-...- & 93.8 & 0.5 & -17.1 & -12.5 \\
\hline & $\begin{array}{l}20 \mathrm{ml} \text { of ether }+0.5 \mathrm{ml} \text { of meth- } \\
\text { anol. }\end{array}$ & Included in solvent. & 28.1 & & 71.9 & 0 & -5.7 & +8.3 \\
\hline XI $\ldots$ & $\begin{array}{l}20 \mathrm{ml} \text { of benzene }+0.5 \mathrm{ml} \text { of } \\
\text { methanol }\end{array}$ & Included in solvent. & 25.2 & -.. & 74.8 & 0 & -9.9 & +5.5 \\
\hline
\end{tabular}

- Specific rotation, based on the weight of the acetylsugars, the acetylglycosides, and the orthoester formed from $2 \mathrm{~g}$ of the acetylglycosyl bromide.

In contrast to the results obtained with tetraacetyl- $\alpha$-D-mannosyl bromide, the reaction products from tetraacetyl- $\alpha$-D-glucosyl bromide (a cis halide) show considerably less variation with change of solvent. The effect of competition of the methanol and water for the glycosidic carbon is evidenced in the increase of the free acetylsugar when the amount of the methanol is small. The absence of the methyl orthoacetate and the alpha acetylglycoside in the reaction products clearly supports the prior concept that cis acetylglycosyl halides are incapable of reaction by the orthoester mechanism. That is, the reaction takes place almost entirely by an opposite-face attack on the glycosidic carbon by nucleophilic substances in the environment (eq 3). Since the alpha acetylglycoside is not found in the product, there is no evidence for the coordination of ether or benzene with the glycosidic carbon, since such coordination would yield the alpha acetylglycoside by a second opposite-face attack.

In all cases, the reaction products from tetraacetyl- $\alpha$-D-mannosyl bromide and tetraacetyl-
$\alpha$-D-glucosyl bromide mutarotate in the dextro direction. In other words, the beta modification of the free acetylsugars predominates in the prodducts, as required by the reaction mechanisms previously discussed.

\section{Effect of Temperature on the Koenigs-Knorr Reaction}

In the preceding section it was emphasized that the intramolecular reaction of tetraacetylmannosyl bromide with methanol at $20^{\circ} \mathrm{C}$ takes place through a solvated orthoester intermediate with the exclusive formation of the methyl orthoacetate. Inasmuch as this result is at variance with the conclusion of Winstein and coworkers, based on a study of the acetolysis of trans-2-acetoxycyclohexyl $p$-toluenesulfonate at $75^{\circ}$ and $100^{\circ} \mathrm{C}$, it seemed desirable to investigate the effect of temperature on the course of the Koenigs-Knorr reaction. ${ }^{5}$ The data of table 2 show that the composition of the product from tetraacetyl-

\footnotetext{
${ }^{5}$ It was observed previously that the formation of orthoesters is favored by low temperatures [8].
} 
TABLE 2. Effect of temperature on composition of products from reaction of acetylglycosyl bromides with methanol in the presence of silver carbonate

\begin{tabular}{|c|c|c|c|c|c|c|c|}
\hline \multirow[b]{2}{*}{ Experiment number } & \multirow[b]{2}{*}{ Temperature } & \multicolumn{4}{|c|}{ Molecular composition of product } & \multicolumn{2}{|c|}{ Optical rotation of product } \\
\hline & & Acetylsugar & $\begin{array}{l}\text { Acetylortho- } \\
\text { acetate }\end{array}$ & $\begin{array}{l}\text { Beta acetyl- } \\
\text { glycoside }\end{array}$ & $\begin{array}{l}\text { Alpha acetyl- } \\
\text { glycoside }\end{array}$ & $\begin{array}{c}{[\alpha]_{\mathrm{D}}^{20} \text { at }} \\
60 \mathrm{~min} \\
(\mathrm{MeOH})\end{array}$ & $\begin{array}{c}{[\boldsymbol{\alpha}]_{\mathrm{D}}^{20} \text { at }} \\
\text { equilibrium } \\
\left(\mathrm{CHCl} \mathrm{CH}_{3}\right)\end{array}$ \\
\hline \multicolumn{8}{|c|}{ Product from tetraacetyl- $\alpha$-D-mannosyl bromide } \\
\hline $\begin{array}{l}\text { VII } \\
\text { I } \\
\text { VIII }\end{array}$ & $\begin{array}{r}{ }^{\circ} C \\
-15 \\
20 \\
50\end{array}$ & $\begin{array}{c}\text { Percent } \\
6.2 \\
6.9 \\
13.5\end{array}$ & $\begin{array}{c}\text { Percent } \\
78.1 \\
78.5 \\
53.4\end{array}$ & $\begin{array}{c}\text { Percent } \\
15.7 \\
14.6 \\
25.1\end{array}$ & $\begin{array}{l}\text { Percent } \\
\quad 0 \\
0 \\
8.0\end{array}$ & $\begin{array}{l}-35.7^{\circ} \\
-32.2 \\
-22.2\end{array}$ & $\begin{array}{l}-29.0^{\circ} \\
-27.7 \\
-19.8\end{array}$ \\
\hline \multicolumn{8}{|c|}{ Product from tetraacetyl- $\alpha$-D-glucosyl bromide } \\
\hline $\begin{array}{l}\text { XII } \\
\text { IX } \\
\text { XIII }\end{array}$ & $\begin{array}{r}-15 \\
20 \\
50\end{array}$ & $\begin{array}{l}5.0 \\
5.7 \\
6.7\end{array}$ & - & $\begin{array}{l}94.3 \\
93.8 \\
90.8\end{array}$ & $\begin{array}{r}0.7 \\
.5 \\
2.5\end{array}$ & $\begin{array}{l}-16.5 \\
-17.1 \\
-12.6\end{array}$ & $\begin{array}{r}-12.9 \\
-12.5 \\
-8.6\end{array}$ \\
\hline
\end{tabular}

glucosyl bromide did not change significantly in the range from $-15^{\circ}$ to $20^{\circ} \mathrm{C}$; the reaction product, aside from the acetylsugar, ${ }^{6}$ was almost exclusively the beta acetyglucoside. Since an intramolecular reaction is stereomerically impossible for tetraacetyl- $\alpha$-D-glucosyl bromide, the amount of the beta acetylglucoside may be taken as a measure of the intermolecular reaction with methanol. At $50^{\circ} \mathrm{C}, 2.5$ percent of the alpha acetylglucoside was formed; the increase over that at $20^{\circ} \mathrm{C}$ may be due to recemization through a carbonium ion (the $\mathrm{S}_{N} 1$ mechanism of Gleave, Hughes, and Ingold [9]).

In contrast to the results obtained with tetraacetylglucosyl bromide, the results with tetraacetylmannosyl bromide show a striking effect of temperature on the course of the reaction at $50^{\circ} \mathrm{C}, 7^{7}$ although the composition of the product was substantially the same at $-15^{\circ}$ and $20^{\circ} \mathrm{C}$. Since no alpha acetylmannoside was found at low temperatures, the amount of the orthoester can be taken as a measure of the intramolecular reaction at $20^{\circ} \mathrm{C}$ or below. Presumably the amount of the beta acetylmannoside, by analogy to the glucose series, is a measure of the intermolecular reaction. When the temperature was raised to $50^{\circ} \mathrm{C}$, the yield of orthoester dropped from 78 to 53 percent, and the yields of the alpha and beta acetylmannosides increased; the former

\footnotetext{
${ }_{6}^{6}$ The formation of the acetylsugar as a byproduct was discussed on page 163 , and will not be considered here.

7 To show that the differences in the amounts of orthoester and alpha acetylmannoside found at $20^{\circ}$ and $50^{\circ} \mathrm{C}$ were real and not due to a secondary decomposition of the orthoester after its formation, a sample of triacetylmannose 1,2 -(methyl orthoacetate) was heated at $50^{\circ} \mathrm{C}$ with methanol under the conditions used in the replacement reactions. No change was found.
}

from 0 to 8 percent, the latter from 16 to 25 percent. The increase in the beta acetylmannoside is evidence that at the higher temperature the intermolecular reaction is favored at the expense of the intramolecular. This may be due to the fact that less favorable conditions exist at $50^{\circ}$ than at $20^{\circ} \mathrm{C}$ for the intramolecular reaction to take place, because of alteration in the positions of the reactive groups within the molecule. Certain conformations of the pyranose ring place the halogen and the acetyl group in stereomerically favorable positions for intramolecular reaction by the opposite-face mechanism; others do not. At the higher temperature, increased kinetic disturbance of the sugar molecule may alter ring conformation and thus affect the probability of reaction by the orthoester mechanism.

The increase in the alpha acetylmannoside at high temperatures is proportionately greater than the increase in the alpha acetylglucoside. Hence an intermolecular reaction, with an $\mathrm{S}_{N} 1$ mechanism such as that postulated for the formation of the alpha acetylglucoside, does not adequately account for the facts. It seems more probable that the marked increase in the yield of the alpha acetylmannoside at the higher temperature is caused by a modification of the intramolecular course. One would expect the solvated orthoester intermediate, which in the mannose series yields the methyl orthoester almost exclusively at low temperatures, to dissociate at higher temperatures with the formation of the free orthoester ion of Winstein and coworkers. The free ion, by reaction with methanol, would produce the orthoester and the 
alpha acetylglycoside in proportions different from those characteristic of the solvated intermediate in which methanol is already in position to yield the orthoester. ${ }^{8}$ In this connection it should be pointed out again that the experiments that Winstein and coworkers claim to rule out the solvated orthoester mechanism were conducted at relatively high temperatures. The results given in this paper indicate that at low temperatures the intramolecular reaction takes place exclusively through the solvated orthoester intermediate, but at high temperatures part of the reaction takes place through the free ion.

\section{Experimental Procedure}

\section{Discussion of the Analytical Method}

The method for the analysis of the reaction products is based on the premise that the only substances present are the alpha and beta methyl tetraacetylglycosides, the methyl orthoacetate, and the iree acetylsugar. It has been found possible to determine the amount of the acetylsugar by modification of the conventional method for the iodimetric determination of aldoses. The acetylsugar initially formed in the reaction is gradually converted to the alpha-beta equilibrium mixture; in the presence of a catalyst this equilibrium may be established quickly. From the known optical rotation of the pure acetylsugar in equilibrium, and the known amount of this substance in the mixture, it is possible to calculate the contribution of the acetylsugar to the equilibrium rotation of the reaction product. To determine the amount of the orthoester, advantage is taken of the observation [10] that methyl orthoacetates react rapidly with hydrogen chloride in chloroform and that the reaction is accompanied by a large change in optical rotation. Normal methyl acetylglycosides and the free acetylsugars are substantially inert to this reagent. Thus the difference between the rotation at equilibrium and the rotation after the addition of hydrogen chloride is a measure of the amount of orthoester present. The contribution of the orthoester to the equilibrium rotation can be calculated from the amount of orthoester in the reaction mixture and the known optical rotation of the pure substance. The residual optical rotation, after allowance is

\footnotetext{
8 Both the solvated and the free orthoester ion can yield the orthoester and the alpha acetylglycoside. It is noteworthy that both products were separated by application of the Koenigs-Knorr reaction to heptaacetyl-4glucosido-mannosyl bromide at $0^{\circ} \mathrm{C}[10]$.
}

made for the contributions of the acetylsugar and the orthoester, is due to the mixture of the alpha and beta methyl acetylglycosides. After the determination of the acetylsugar and orthoester, the total yield of the acetylglycosides can be obtained by difference, and the proportions of the two acetylglycosides can be calculated from the residual rotation and the known optical rotations of the two substances.

By the procedure outlined in the preceding paragraph the yields of the acetylsugar, the methyl orthoacetate, and the alpha and beta methyl acetylglycosides from tetraacetyl- $\alpha$-D-mannosyl bromide were determined. Application of the same method to the product from tetraacetyl- $\alpha$ D-glucosyl bromide showed the absence of the methyl orthoacetate and gave the yields of the acetylsugar, and the alpha and beta methyl acetylglucosides.

The procedure was standardized by measurements made with the pure constituents as controls. The method for determining the orthoester, although convenient, is not very satisiactory because of the difficulty in maintaining a chloroform solution of hydrogen chloride of uniform strength. Because of variation in this reagent, it was necessary to standardize the procedure for each set of determinations by use oî pure triacetylmannose 1,2-(methyl orthoacetate). Since the quantity of the methyl acetylglycosides was obtained by difference, the values recorded for these substances are subject to the combined errors in the values for the methyl orthoacetate and the free acetylsugar. In the experiments in which the percentage of the methyl acetylglycoside is shown as zero, the optical rotation for the methyl acetylglycoside fraction was calculated to be at least as great in the levo direction as that required for the beta acetylglycoside.

\section{Experimental Details}

(a) Materials

The ether and benzene used as solvents were of analytical grade, dried by sodium, and ireshly distilled. The chloroform was USP grade. The methanol was dried by refluxing with barium oxide and distilling immediately before use.

The hydrogen chloride-chloroform reagent was prepared by passing dry hydrogen chloride into USP chloroform to the point of saturation at $20^{\circ} \mathrm{C}$. The reagent was protected from atmospheric moisture and dispensed from a buret. 
The silver carbonate was prepared by the addition of aqueous sodium bicarbonate to an aqueous silver nitrate solution. It was collected on a filter and thoroughly washed, first with water, and finally with acetone. It was then dried at room temperature in the absence of light in a vacuum desiccator containing phosphoric anhydride.

The Drierite was finely powdered and was redried at $230^{\circ} \mathrm{C}$ immediately before use. The following substances were prepared by the methods given in the corresponding literature references: tetraacetyl- $\alpha$-D-mannosyl bromide [11], tetraacetylmannose [12], methyl tetraacetyl- $\alpha$-D-mannoside [13], methyl tetraacetyl- $\beta$-D-mannoside [14], triacetylmannose 1,2-(methyl orthoacetate) [13], tetraacetyl- $\alpha$-D-glucosyl bromide, page 500 of [15], tetraacetylglucose [16], methyl tetraacetyl- $\alpha$-Dglucoside [1], methyl tetraacetyl- $\beta$-D-glucoside [1] and page 516 of [15].

(b) Method of Conducting the Replacement Reactions

The replacement reactions were conducted in $100-\mathrm{ml}$ glass-stoppered flasks, carefully dried before use, and maintained at the temperature of the experiment by use of a suitable constanttemperature bath. Silver carbonate $(2 \mathrm{~g})$, Drierite $(2 \mathrm{~g})$, and the solvent were placed in the reaction flask and brought to temperature. The acetylglycosyl halide in a glass boat $(2 \mathrm{~g})$ was dropped into the flask, and the mixture was shaken for 15,30 , or $60 \min ^{9}$ according to whether the temperature was $50^{\circ}, 20^{\circ}$ or $-15^{\circ} \mathrm{C}$, respectively. In some of the experiments, the methanol was introduced into the flask as the solvent or as a constituent of the solvent prior to the addition of the halide. In other experiments, $15 \mathrm{ml}$ of a solvent was added at the beginning; after introduction of the silver carbonate, Drierite, and acetylglycosyl halide, $5 \mathrm{ml}$ of the solvent containing $0.5 \mathrm{ml}$ of methanol was added dropwise from a buret with exclusion of moisture by use of a rubber dam. After the reaction was completed, the mixture was filtered, the residue was washed with methanol, and the filtrate and washings were made to a volume of $50 \mathrm{ml}$ with methanol. Portions of this solution were used for the measurements that follow.

\section{(c) Analysis of the Reaction Product}

(1) Determination of the free acetylsugar.Twenty milliliters of the solution containing the

\footnotetext{
$\checkmark$ The reaction times were so selected that the filtered reaction products were halogen-free.
}

reaction product was evaporated to dryness in a current of dry air, and the last trace of alcohol was removed by the addition of $5 \mathrm{ml}$ of benzene and re-evaporation. The residue was taken up in $5 \mathrm{ml}$ of peroxide-free dioxane, and the free acetylsugar was determined by oxidation with iodine by the method of Kline and Acree [17]. Control experiments showed that neither the methyl acetylglycosides nor triacetylmannose 1,2-(methyl orthoacetate) reacts with iodine, whereas tetraacetylmannose and tetraacetylglucose react stoichiometrically when an excess of 5 to $10 \mathrm{ml}$ of $0.1-N$ iodine solution is used. The amount of free acetylsugar in the entire reaction product was calculated, and expressed in tables 1 and 2 as percentage of the acetylsugar theoretically equivalent to the acetylglycosyl halide employed.

(2) Optical rotation of the reaction mixture at equilibrium.-Preliminary experiments showed that the equilibrium of the free acetylsugars can be established readily by the addition of sodium acetate, without alteration of the rotation of the methyl acetylglycosides or of triacetylmannose 1,2-(methyl orthoacetate). Hence, sodium acetate was employed as catalyst to establish equilibrium. Ten milliliters of the solution containing the reaction product was evaporated to dryness in a $25-\mathrm{ml}$ volumetric flask containing $0.05 \mathrm{~g}$ of crystalline sodium acetate. Sufficient USP chloroform was added to make a volume of $25 \mathrm{ml}$ at $20^{\circ} \mathrm{C}$. After $18 \mathrm{hr}$ at room temperature, the chloroform solution was filtered, and the optical rotation was read in a 4 -dm tube. The readings are recorded in table 3 , and the corresponding specific rotations are given in tables 1 and 2 .

(3) Optical rotation of the reaction mixture at 60 minutes.- Since the solution exhibits mutarotation because of the presence of the free acetylsugar, measurements of optical activity were made on the methanol solution of the reaction product at convenient times and were extrapolated to obtain the values at $60 \mathrm{~min}$ from the beginning of the reaction. These values were converted to specific rotations based on the weight of the reaction products. ${ }^{10}$

\footnotetext{
10 Since the acetylglycosyl bromide (of molecular weight 411.21) is con verted to the free acetylsugar (of molecular weight 348.30) and to the methyl acetylglycosides and methyl acetylorthoester (of molecular weight 362.33), the weight of reaction product from $2 \mathrm{~g}$ of acetylglycosyl bromide is

$$
2\left[\frac{348.30}{411.21} A+\frac{362.33}{411.21}(1-A)\right],
$$

where $A$ is the fraction of the acetylglycosyl bromide converted to the free acetylsugar, as determined by titration.
} 
TABLE 3.-Experimental data on products derived from acetylglycosyl bromides at $20^{\circ} \mathrm{C}$

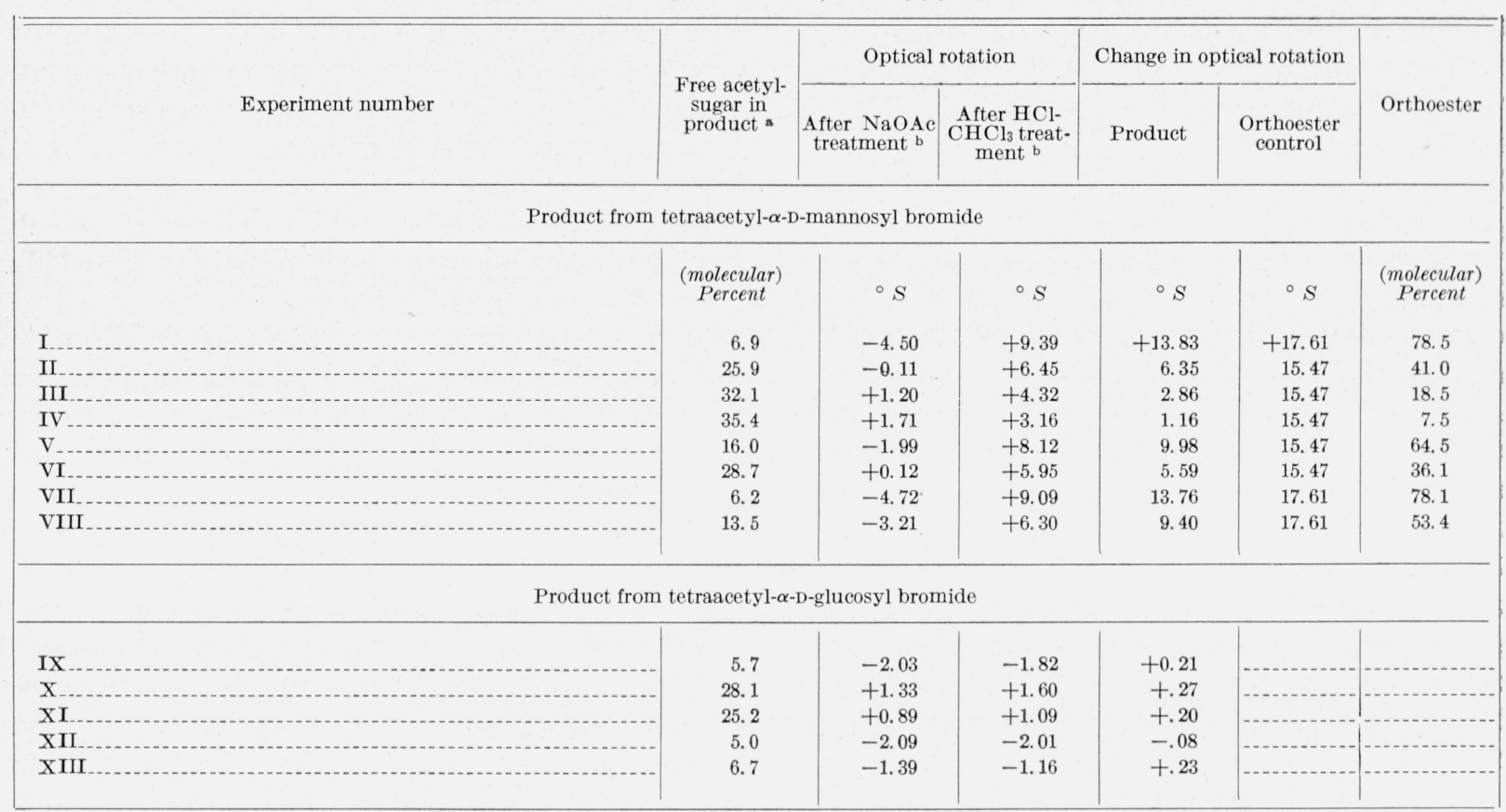

- Determined as described on page 168.

b 0.000973 moles in a volume of $25 \mathrm{ml}$, read in a 4 -dm tube.

In order to evaluate the contributions of the several constituents of the product to the equilibrium rotation, the measurements given in table 4 were made with the pure substances under conditions like those used in the study of the reaction products. To obtain the equilibrium rotation, a 0.000973 -mole sample of the substance in a $25-\mathrm{ml}$ volumetric flask was dissolved in $10 \mathrm{ml}$ of methanol; $0.05 \mathrm{~g}$ of sodium acetate was added, and the mixture was evaporated to dryness. The material was then dissolved in chloroform, the volume was adjusted to $25 \mathrm{ml}$, and the optical rotation was measured in the manner described for obtaining the equilibrium rotation of the reaction product. The observed rotations of $+3.20^{\circ} \mathrm{S}$ and $+12.49^{\circ} \mathrm{S}$ for tetraacetylmannose and tetraacetylglucose, respectively, and of $-4.32^{\circ} \mathrm{S}$ for triacetylmannose 1,2-(methyl orthoacetate) were used to calculate the contributions of these three substances to the equilibrium rotations of the reaction products. The values of $+7.95^{\circ} \mathrm{S}$ and $-7.84^{\circ} \mathrm{S}$ were used to calculate the proportions of the alpha and beta methyl tetraacetylmannosides from the residual rotations, as described on page 167 . The values of $+21.20^{\circ} \mathrm{S}$ and $-3.03^{\circ}$ $\mathrm{S}$ were used for similar calculations for the alpha and beta methyl tetraacetylglucosides. The spe- cific rotations for the glycoside fractions of the products from experiments I and VII in the mannose series were calculated to be $-56.3^{\circ}$ and $-60.7^{\circ}$, respectively. These are higher values in the levo direction than the specific rotation, $-48.2^{\circ}$ of the methyl tetraacetyl- $\beta$-D-mannopyranoside. However, repetition of the experiments gave results in substantial agreement with those reported. Since the rotations of the glycoside fractions are based on only 15 percent of the product and are obtained by difference, they are greatly affected by all errors of measurement.

Better agreement was found in the glucose series in which experiments IX, X, XI, and XII gave specific rotations of $-17.9^{\circ},-18.6^{\circ},-18.5^{\circ}$, and $-17.5^{\circ}$, respectively, for the glycosidic fractions in comparison with $-18.6^{\circ}$ for the specific rotation of methyl tetraacetyl- $\beta$-D-glucopyranoside.

(4) Determination of the orthoester.-Ten milliliters of the methanol solution of the reaction product was evaporated in a current of dry air in order to remove the alcohol. The residue was dissolved in the hydrogen chloride-chloroform reagent, and the volume was adjusted to $25 \mathrm{ml}$. The optical rotation was read in a 4 -dm tube, 30 min after the addition of the reagent, and 
recorded in table 3 . It was mentioned earlier that the method was standardized for each measurement in the mannose series by a control experiment with pure triacetylmannose 1,2-(methyl orthoacetate). The change in optical rotation for the control applicable to each experiment is also given in table 3 .

The effect of the addition of the $\mathrm{HCl}$ reagent on the optical rotations of tetraacetylmannose, tetraacetylglucose, and the alpha and beta methyl tetraacetylglycosides of mannose and glucose was measured in separate experiments, and the results are recorded in table 4 . The addition of the $\mathrm{HCl}$ reagent did not cause an appreciable change in the rotations of the glycosides and of tetraacetylglucose. A small change was observed in the rotation of tetraacetylmannose; in the calculation of the amount of orthoester, allowance was made for the corresponding change in the rotation of the acetylmannose present in the product. In each case the correction amounted to $0.8^{\circ} \mathrm{S} \times \%$ of free acetylsugar/100. The changes in optical rotation for the product recorded in table 3 were corrected for this factor. The percentage of the orthoester in the product was obtained from the ratio of the corrected change and the change found for the pure substance.

TABLE 4. Experimental data obtained with pure compounds

\begin{tabular}{|c|c|c|}
\hline \multirow{2}{*}{ Reference substance } & \multicolumn{2}{|c|}{ Optical rotationa } \\
\hline & $\begin{array}{c}\text { After } \mathrm{NaOAc} \\
\text { treatment }\end{array}$ & $\begin{array}{l}\text { After } \mathrm{HCl}- \\
\mathrm{CHCl} 1_{3} \text { treat- } \\
\text { ment }\end{array}$ \\
\hline Tetraacetyl-D-mannose & $\begin{array}{c}{ }^{\circ} S \\
+3.20\end{array}$ & $\begin{array}{c}{ }^{\circ} \mathrm{S} \\
+4.02\end{array}$ \\
\hline Tetraacetyl-D-glucose_.... & +12.49 & +12.31 \\
\hline $\begin{array}{l}\text { Methyl tetraacetyl- } \alpha \text {-D-mannopyranoside } \\
\text { Methyl tetraacetyl- } \beta \text {-D-mannopyrano- } \\
\text { side }\end{array}$ & $\begin{array}{l}+7.95 \\
-7.84\end{array}$ & $\begin{array}{l}+8.01 \\
-7.80\end{array}$ \\
\hline Methyl tetraacetyl- $\alpha$-D-glucopyranoside & +21.20 & +21.21 \\
\hline $\begin{array}{l}\text { Methyl tetraacetyl- } \boldsymbol{\beta} \text {-D-glucopyranoside } \\
\text { Triacetylmannose } 1,2 \text {-(methyl ortho- } \\
\text { acetate) }\end{array}$ & -3.03 & -3.02 \\
\hline $\begin{array}{c}\text { Triacetylmannose } 1,2 \text {-(methyl ortho- } \\
\text { acetate) }\end{array}$ & -4.32 & $\mathrm{~b}+13.30$ \\
\hline
\end{tabular}

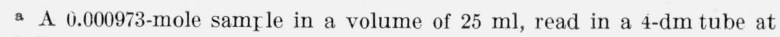
$20^{\circ} \mathrm{C}$.

b The values were obtained with different preparations of the $\mathrm{HCl}-\mathrm{CHCl}_{3}$ reagent.

\section{Summary}

A study has been made of the effect of solvent and temperature on the course of certain organic replacement reactions. It was formerly postulated $[2,3,4]$ that the reaction of trans acetylglycosyl halides with compounds containing a free hydroxyl group $(\mathrm{ROH})$ takes place both by an opposite-face intermolecular course and by an opposite-face intramolecular course involving a solvated orthoester intermediate. The former yields the glycoside with inversion, the latter an orthoester ion, which then stabilizes by one of two mechanisms to yield either the orthoester or the glycoside with apparent retention of configuration. In this paper it has been shown that if the orthoester ion is solvated, the course of the intramolecular reaction should be drastically affected by a solvent that is able to coordinate in the formation of the orthoester ion, but unable to eliminate a proton. On the other hand, if the orthoester intermediate exists as a free ion, such a solvent should act only as an inert diluent in the reaction. A quantitative study has been made of the reaction with methanol of tetraacetyl- $\alpha$-D-glucosyl bromide (a cis halide), and tetraacetyl- $\alpha$-D-mannosyl bromide (a trans halide) in the presence of silver carbonate (the Koenigs-Knorr reaction). At $-15^{\circ}, 20^{\circ}$, and $50^{\circ} \mathrm{C}$, tetraacetyl- $\alpha$-D-glucosyl bromide yielded almost exclusively methyl tetraacetyl- $\beta$-D-glucoside. At $20^{\circ} \mathrm{C}$ and below, tetraacetyl- $\alpha$-Dmannosyl bromide yielded 78 percent of triacetylmannose 1,2-(methyl orthoacetate) and 15 percent of methyl tetraacetyl- $\beta$-D-mannoside. No methyl tetraacetyl- $\alpha$-D-mannoside was formed, a result that indicates that conversion of the orthoester intermediate to the orthoester is the preferred course when methanol alone is present. In the presence of ether and small quantities of methanol, tetraacetyl- $\alpha$-D-mannosyl bromide yielded 7.5 percent of the orthoester, 23 percent of the beta acetylglycoside and 34 percent of the alpha acetylglycoside. The effect of benzene on the proportion of the products was similar to that of ether but less pronounced, in accord with its smaller tendency to co-ordinate. These striking changes support the mechanism involving a solvated orthoester intermediate rather than a free ion.

When the temperature of the reaction was raised to $50^{\circ} \mathrm{C}$, the amount of the orthoester dropped from 78 to 53 percent, and 8 percent of the alpha acetylmannoside was formed. This shift in the proportions of the products of the intramolecular reaction seems to indicate that the solvated orthoester ion is somewhat thermally unstable, and that part of the reaction at the higher 
temperature takes place through the free orthoester intermediate. This would react to yield the orthoester and the alpha acetylglycoside in different proportions from the solvated ion. The reaction of tetraacetyl- $\alpha-D-$ glucosyl bromide was only slightly affected by a change of solvent or of temperature. This is compatible with the stereomeric inability of the alpha glucose configuration to form an orthoester intermediate.

The authors express their appreciation to Nancy B. Holt for her assistance in conducting the analytical work reported in this paper.

\section{References}

[1] W. Koenigs and E. Knorr, Ber. deut. chem. Ges. 34, 957 (1901).

[2] H. S. Isbell, Ann. Rev. Biochem. 9, 65 (1940).

[3] H. L. Frush and H. S. Isbell, J. Research NBS 27, 413 (1941) RP1429.

[4] H. L. Frush and H. S. Isbell, J. Research NBS 34, 111 (1945) RP1663.

[5] S. Winstein and R. E. Buckles, J. Am. Chem. Soc. 64, 2780, 2787 (1942).
[6] S. Winstein, C. Hanson, and E. Grunwald, J. Am. Chem. Soc. \%o, 812 (1948).

[7] D. D. Reynolds and W. L. Evans, J. Am. Chem. Soc. 60, 2559 (1938).

[8] W. W. Pigman and H. S. Isbell, J. Research NBS 19, 199 (1937) RP1021.

[9] J. L. Gleave, E. D. Hughes, and C. K. Ingold, J. Chem. Soc. 1935, 236; E. D. Hughes, J. Chem. Soc. 1946, 968.

[10] H. S. Isbell, BS J. Research 7, 1115 (1931) RP392.

[11] F. Micheel and H. Micheel, Ber. deut. chem. Ges. 63, 386 (1930); D. H. Brauns, BS J. Research 7, 573 (1931) RP358.

[12] P. A. Levene and R. S. Tipson, J. Biol. Chem. 90, 89 (1931).

[13] J. K. Dale, J. Am. Chem. Soc. 46, 1046 (1924).

[14] H. S. Isbell and H. L. Frush, J. Research NBS 24, 125 (1940) RP1274.

[15] F. J. Bates and associates, Polarimetry, saccharimetry and the sugars, NBS Circular C440 (1942).

[16] E. Fischer and K. Hess, Ber. deut. chem. Ges. 45, 912 (1912).

[17] G. M. Kline and S. F. Acree, BS J. Research 5, 1081 (1930) RP247.

Washington, May 12, 1949. 